\title{
Successful Leadership Practice in School
}

\author{
- Kamal Prasad Koirala \\ Lecturer, Gorkha Campus, Gorkha
}

\begin{abstract}
This paper mainly focuses on successful leadership practices in secondary school. It aims to identify the recent models and theories of successful leadership practice in schools, and explore the experience of school principal regarding successful school leadership in the Nepalese context. A qualitative study was carried out in Gorkha district for the collection of data. A successful head teacher was selected for in-depth interview to explore the perception and experience about successful practice of school leadership. The findings of the study reveal that strong interpersonal skills, people-centered leadership, clear communication of vision and goal, focus on academic achievement, co-curricular activities, transparency, creating a positive work environment, knowledge of pedagogical contents, and cooperation and collaboration with various stakeholders are the vital constituents of successful leadership practices.
\end{abstract}

Keywords/terms: Leadership practice, successful leadership, school achievement, learning environment

\section{Context of the study}

I would like to begin by sharing an incident I came across some 26 years ago when I passed the lower secondary level from Shree Himalaya Lower Secondary School of Gorkha district. I had heard about well-known high schools of Northern Gorkha district including Paropakar High School, Joubari; Surya Jyoti High School, Taku; and Dullav High School, Ghyampesal. But, I did not know why these schools were popular at that time. I had chosen Shree Himalaya Secondary School, Jhyawa for my convenience to complete SLC. When I was studying there, I found that the school had been established about five years ago. There was a lack of professionally and academically sound school leader. The teaching staffs were also not academically qualified and sound in their subject matter. I had come to know more about Dullav Secondary School and Surya Jyoti Secondary School when I was taking a coaching class in Paropakar Secondary School to prepare for SLC examination. I had found these schools 
had long history and had been led by academically and professionally sound leaders such as Ghana Prasad Dhakal, Bir Bahadur Gurung and Chandika Bhatta. So, the performance of these schools was better than other schools.

After completing Master's Degree nearly fourteen years ago, I started teaching in Paropakar Secondary School. I found some political influences in school administration from some political leaders. But the students and parents were aware of the performance of the school; so they strongly supported the school head teacher. Despite having the strong support of students and parents, it was due to political instability that the head teacher was not so much satisfied to lead the school. The school's performance was also worsening in the final years of his tenure.

Thereafter, I was shifted to Shree Shakti Secondary School located in the district headquarter, which was a renowned high school of Gorkha district having long history. About 900 students were enrolled in that school in 2064-065 BS and the school performance was also good. Political influence appeared to be decisive in that school too in recruiting teachers and forming School Management Committee. The head teacher was forced to resign because of the lack of cooperation from teachers and staff. Then another teacher of the same school was appointed as the head teacher.

I heard that the school performance and the number of students were going down in the school year by year. The situation was almost same even in Shakti Secondary School having about five hundred students. This school also performed poorly in last year grade VIII and Secondary Education Examination (SEE) result. On the other hand, Saraswoti Secondary School, a community school, situated in the district headquarter, was improving its performance as well as its student enrollment. I was impressed by the school's performance, so I shifted my kids to that school. One of them completed SEE with A+ grade and is now studying grade XI in Kathmandu.

As a parent, I visited the school several times and realized that the Principal was successfully leading the School. I was unaware about school leadership practice but only understood that there were good, qualified and trained teachers so that school performance and quality of teaching-learning was improving. As a result, many parents preferred that school for their kids. When I studied leadership in education during my M. Phil., I learned that successful school leadership depends on the successful school principals. 
This invoked me to answer the questions: Why are all schools from same geographical area not able to achieve similar level of academic achievement? What are the causes of successful schools? How do the successful school head teachers collaborate and cooperate with the students, teachers and parents? To answer these queries, I had chosen the head teacher of Saraswati Secondary School to find out the importance of knowing the perception and experience of a school head teacher for successful practices of leading a school.

Successful school leaders are those who respond most appropriately to the demands of the specific situation. Contexts are unique to schools and are, thus, varied among schools, even if they are located within the same geographical location. A range of contextual factors affect schools within a locality as well as across locality such as location of school, history, stage of development, leadership structure, instructional program, staff competence and professional disposition, diversity of student population, available resources and school culture (Weinstein and others, 2017). Although all schools in Nepal are centralized under the Ministry of Education, Science and Technology; they operate under different situational factors depending on geographical location, student diversity, size of student population, and available resources (Abdullah and others, 2016). In the context of same geographical location, various studies demonstrate that successful leadership practices of school principals show the elements of several established leadership models, which are enacted in response to individual contexts (Gurr, 2015).

The successful principals in Sweden, when faced with low academic performance in their schools, worked towards creating a learning culture in their schools by establishing a robust learning structure (Abdullah and others, 2016). The study of the successful principals of 14 Australian schools demonstrated a high level of personal integrity, sensitivity and appropriate adjustments to their own local contexts in creating a high level of expectations and a conducive learning environment in their schools (Gurr and others, 2010). In the context of Gorkha district, the learning environments in different schools differ, and the environmental factors are also found affecting school leadership.

This literature review clearly demonstrates that different principals, even those working within the same geopolitical context, follow different paths in 
response to their environment, and yet are successful through their contextbased leadership practices (Abdullah and others, 2016). In this regard, my concern is how a principal of Saraswoti Secondary School is successfully leading the school by adjusting different environmental factors and achieving high academic performance.

\section{Successful school leadership model}

The successful leadership practice model developed by Day and others (2013) shows how a school principal can be successful to lead school and in what condition the principal practices this model to lead school successfully.

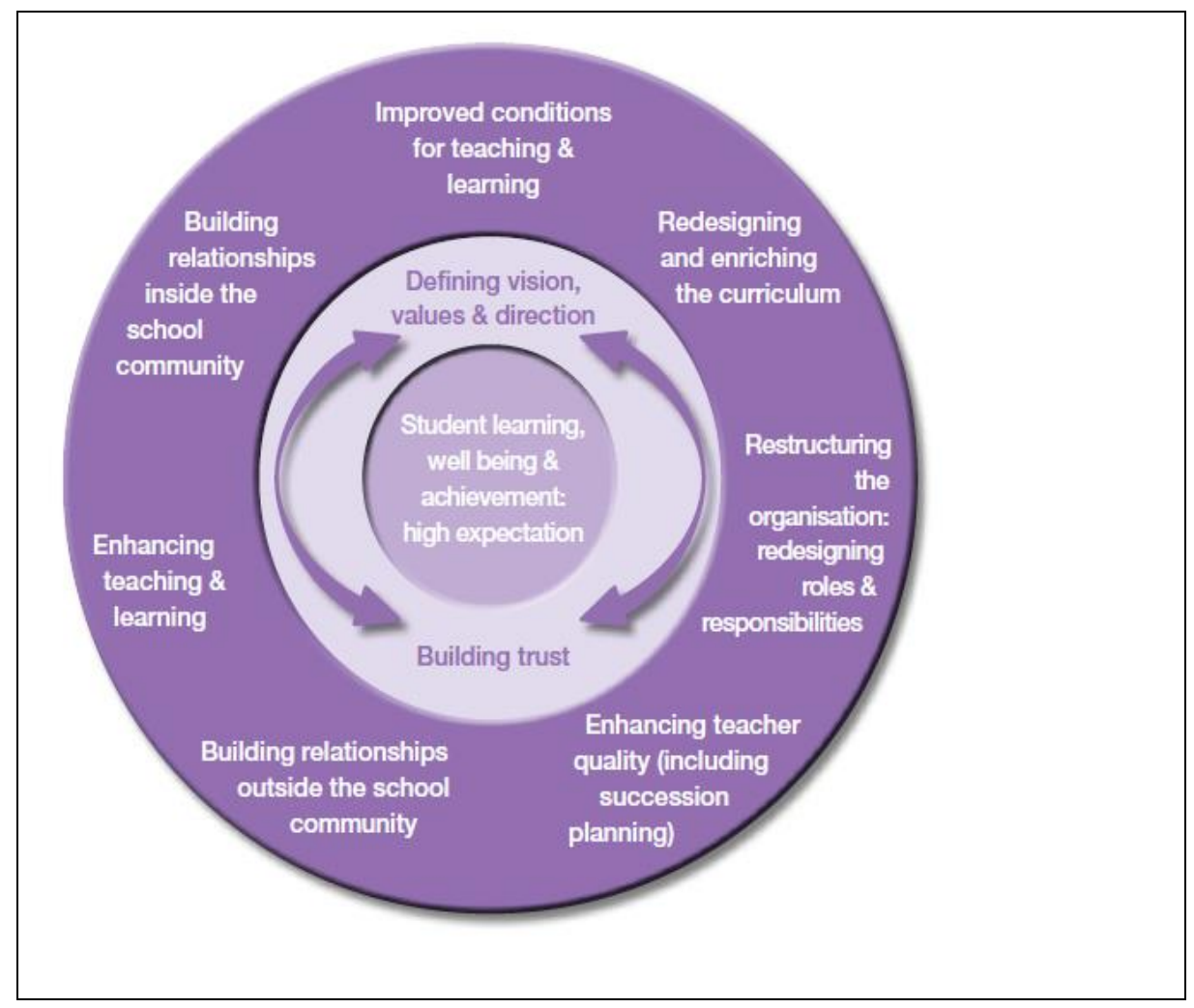

Figure 1: Dimensions of successful leadership practice model developed by Day and others (2013, p. 16) 
A model given by Louis and others (2010) focuses on how various components of successful school leadership practice are interlinked with one another, and how successful leadership depends on the principal's capacity to collaborate with school staff, parents, teachers, students' family, state and district policy makers, and professional leaders to attain student learning outcome.

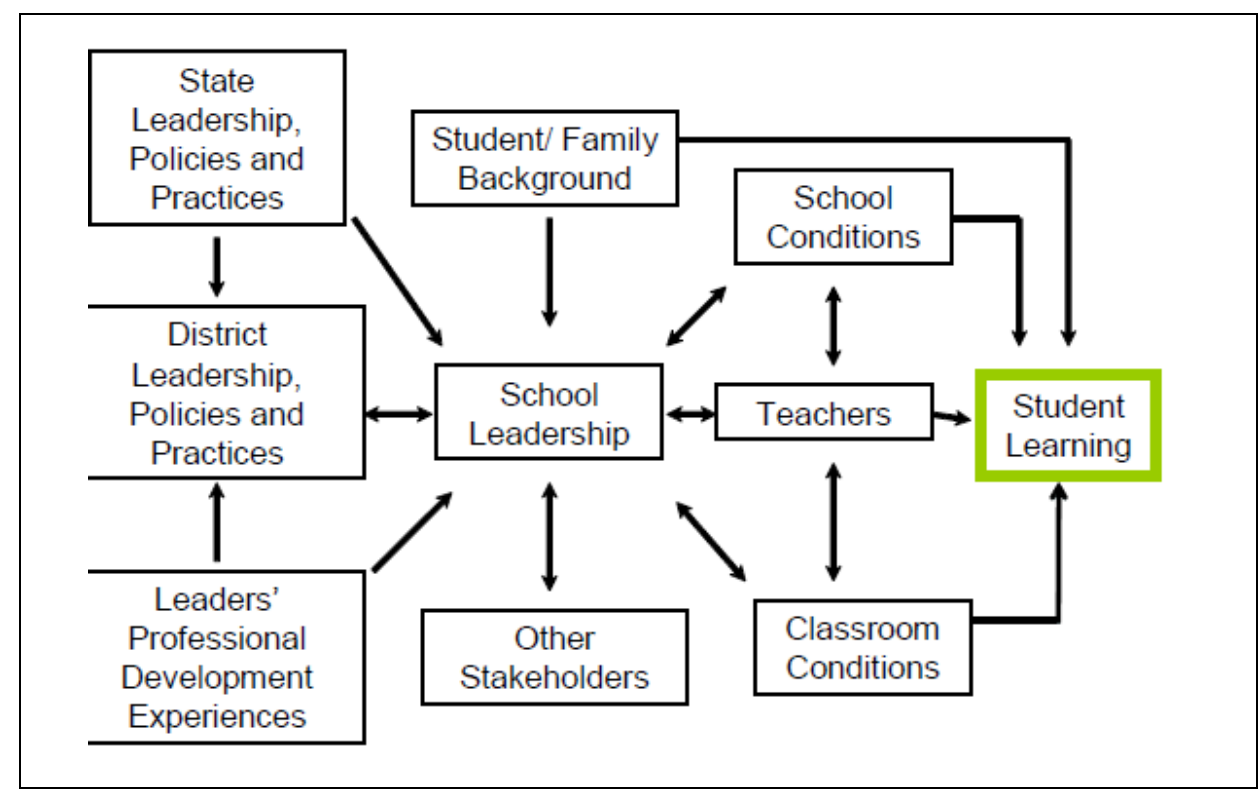

Figure 2: Leadership influences on student learning model developed by Louis and others $(2010, p .14)$

In context of my study, both models can be applicable because both models are based on transformative leadership theory and focus on principal's role to lead the school. This depends on student achievement and the role of the principals to collaborate and cooperate with different stakeholders.

\section{Methods}

This study follows qualitative case study design (Creswell, 2007, 2013; Yin, 2003), which focuses on studying a single head teacher of the school achieving academic success in grade 8 and SEE. I collected the perception and experience on how his leadership practices helped to achieve academic 
excellence in his school (Creswell, 2013; Denzin and Lincoln, 2018). The participant of this study was the head teacher who was teaching in the school for eighteen years and serving as a head teacher for seven years.

My purpose of study was to explore head teacher's perception and experiences about successful school leading practices in present competitive era with high academic achievement. To fulfil my objectives, I selected the principal of Saraswoti Secondary School of Gorkha district purposively (Creswell, 2007, 2013; Denzin and Lincoln, 2005; Yin, 2003) because I was already familiar with the principal and the performance of the school. I wanted to know his perception and experiences on leading the school successfully in collaboration with various social groups. First of all, I informally talked with him about teaching experience and then I recorded about thirty-five-minute in-depth interview. I assured him that his name would not be disclosed without his permission.

Once the data collection procedure was over, the recorded interview was transcribed first in Nepali and then translated into English. Coding the main theme and thematic analysis (Creswell, 2007; Denzin and Lincoln, 2011; Yin, 2003) were done focusing on the model of transformative leadership to draw the findings from his experience for successful school leadership.

For trustworthiness and confidentiality of qualitative data, the transcribed data were verified by the head teacher; then validity and reliability of respondent's version of truth were confirmed by saturation of several interviews as well as day-to-day observation of school environment (Creswell, 2007, 2013; Yin, 2016). From transcribed interview, five main themes were generated, which are discussed in the section that follows.

\section{Result and discussion}

From the analysis of data, it was found that successful school leaders have followed some important practices to lead the school in collaboration with society, as described below under the relevant themes.

\section{Vision and commitment}

Goal setting is considered one of the key dimensions of success for a successful school leader (Harris and others, 2008; Robinson and others, 2009). Successful leaders set realistic goals for their schools and effectively communicate them to the stakeholders in order to acquire collective 
commitment to achieve them (Robinson and others, 2009). My research participant, the Principal of school, claimed that every principal should have clear vision about leading the school ahead and fulfilling the goals. He added that many school principals who do not have any vision and direction to move school forward never achieve academic progress, so they should handover the leadership to a new visionary principal. He added that he had commitments with parents to provide quality education to their children; so he worked to fulfil his commitments collaboratively. Consequently, he is becoming successful in increasing the performance of the school.

His another commitment is transparency. He claimed that good leadership and better school performance depends on transparency. If principals are involved in economic corruption, parents never believe them and they hesitate to send their children in those schools. So, transparency is the first priority. If a principal is ready to show every details to the parents, teachers, management committee and students, they believe in the leadership and can be ready to support school in every respect. Bhattarai claimed that all stakeholders believed his work and became ready to help the school in the case of financial hardship as well. He further claimed that he never compromised transparency in teacher's recruitment to set the school's academic trajectory.

His vision and commitment is found based on the successful school leadership practice model given by Day and others (2013). I found that if the head teacher of a school is loyal to his duty, committed and transparent about school administration, the school's academic performance improves and its positive impact is seen in the society.

\section{Improving curricular and co-curricular activities}

For successful school leader, management of the curricular and co-curricular activities is another challenge. According to the principal, a school cannot be successful in academic performance without curricular and co-curricular activities in the school. According to him, teachers are ready to take extra classes on period basis usually with the expectation of monetary benefit. The school has regularly conducted extra classes in both morning and evening shifts which had helped to complete the course in the prescribed time; and students also have learnt more from teachers. This has ultimately helped to increase students' achievement. He further added that sport programmes also 
increase collaborative working motive among the students. For the recreation of teachers, picnic and other entertainment programmes were regularly conducted by the school. He added that the school has well managed ICT laboratory with internet facilities, so teachers can have the access to additional knowledge using ICT lab. He further added:

I told all the teachers and staff members, 'You should be updated in using the ICT, otherwise you can go to another school or quit your teaching profession; and another qualified person will get the opportunity to work here. He further stated that he had cooperated to get the new knowledge and managed one-month summer vacation teacher training program every year on ICT use and other professional activities, which helped the school in achieving success academically.

Day and others (2013) mention, successful leadership practice model is based on improved condition of teaching and learning; redesigning and enriching the curriculum; and enhancing teaching-learning. My argument is that if all school head teachers are capable to apply the mentioned strategies, student learning, well-being and high level achievement will be possible. For this, authorized institution should manage the training opportunity for concerned head teachers.

\section{Collaboration with stakeholders}

To develop a successful school, all stakeholders need to co-operate and work together to achieve the school goals. Since parents are the direct beneficiary of the services provided by the school (Abdullah and others, 2016) and their involvement is directly linked with student achievement, they become an important element for a school's success. While talking about the positive environment with respect to parents' and students' involvement in the school, the principal has developed excellent relationships with the Ministry of Education Science and Technology, and the District Education Coordination Unit. The principal claims that he has built good rapport with the parents and engages them in consultation, so they are satisfied with the new cooperative culture in the school. The teachers, parents, and students collaborate together, come and sit together and discuss the issues related to academic improvement of school as well as fund raising and finding deficiencies in the school environment, which has helped parents and 
students to feel that they are also active members of the school. He further added that he had collaborated with the relevant government agencies for physical and infrastructure development of the school. Every governmental sector has supported him for creating good learning environmentin school. $\mathrm{He}$ further added that, sometimes, he should be autocratic regarding administrative affairs such as maintaining discipline in the school by the teachers and students. But regarding teaching-learning and other decision making processes, he follows democratic method and also helps teachers and staffs as a facilitator to solve their problems.

School leaders do not get success to run the school smoothly if they want to move alone. Most of the head teachers of different schools do not want to collaborate with teachers, parents, students and school management committee for better student learning. As Louis and others (2010) mention, for students' learning achievement autocratic leadership results in failure these days. I found my participant autocratic regarding the administrative matters, but he is democratic in creating the academic learning environment as well as developing relationship with other stakeholders.

\section{Creating a positive learning environment}

The principal added that he invites parents for consultation and allows ample opportunities for parents and teachers to work together. He further added that he consults students time and again, discusses academic and non-academic issues with them, analyzes exam results and asks for their opinion on making improvements. He organizes events, field trips for teachers and students, separately for each group and occasionally together, where they interact freely and come closer to each other. He further added that he has done regular 'information sharing' and consultation with teachers on all important matters. This has brought the major stakeholders together and created cohesion between them. Thus, he has been successful in building a culture of mutual trust and a positive work environment.

The model of Day and others (2013) as well as that of Louis and associates (2010) focus on on harmonious relationship between inside and outside school environment for better student achievement; and it was found that the principal had implemented both principles. As he mentions, there should be learning opportunity inside school environment for better student learning. Collaboration and co-operation between head teacher and other teaching 
staffs as well as sharing ideas with students also play a crucial role for the development of academic environment inside school. For that purpose, every high school head teacher should build relationship inside the school for creating academically sound environment in pedagogy as well as subject matter. Otherwise they cannot obtain the visions of school in absence of sound academic performance.

\section{Pedagogical content knowledge and school achievement}

Another important successful practice of leadership is pedagogical content knowledge of principals. The principal agreed that every principal should be pedagogically competent and strong in the subject matter to be taught. If principals possess command in the contents, the students, parents and teachers believe them and support their every academic task that ultimately helps increase school achievement. He further claimed that he possesses command both in subject matter and pedagogical knowledge, and had also selected qualified and pedagogically sound teachers without accepting any political pressure. School management committee never intervened in the process of teacher recruitment. He also never compromised with the political leaders on the recruitment of qualified teachers. This was one of the strong factors that helped the school in achieving academic success.

Transformative leadership theory focuses on both pedagogy and content knowledge for successful school leadership practice. Such a characteristic was found in the principal. He was found pedagogically sound and strong in content knowledge.

\section{Conclusion}

As this study indicates, the leadership practice of Saraswoti Secondary School has been based on the leadership theory and model of Day, Harris, Hopkins and Sammons (2013). It revealed that it is not only based on the successful school management practices; rather, it depends on the students' achievement. How school leaders mobilize community, teachers, school staff and other local stakeholders, province and state level government are the basics of a successful school practice in both developed and developing countries. Aforementioned model of a successful school leadership practice reveals that successful leadership practices of school principals cannot be realized without the success of students. Moreover, successful leadership practice of school principal includes the application of transformative and 
pedagogical learning model in their teaching institution in collaboration with various agencies; and such an attempt can secure the complete learning environment in schools. As suggested by different models and theories, the in-depth interview with the successful school head teacher helped me to conclude that good vision and commitment, improving curricular and cocurricular activities, sound knowledge of pedagogical contents, transparency, co-ordination and collaboration with different agencies are the main bases of successful school leadership practice in the present context.

This study had several limitations including the limited time and resource. As only one head teacher was selected as a participant, the conclusion of this study can hardly be generalized. Another limitation is that this study was carried out selecting only one successful secondary school head teacher of Gorkha district, so similar studies need to be carried out covering wide area and more number of such schools so that the results of studies could be generalized. The third limitation is that this study is carried out only to explore the viewpoint of head teacher but not of other teachers, non-teaching staffs, students, parents and school management committee members. If such study includes them, the findings again may vary.

Finally, I also realize that it would be better to follow multimethod to collect the data from informants and to triangulate the data for reliability and validity of the data. In this connection, use of other methods such as observation, focus group discussion, collection of artifacts, etc. would be further relevant. Multiple interviews as well as multimethod data collection procedure would have been ideal for the saturation of the research themes (Creswell, 2007). However, I realize that the data provided by him several times and my analysis of them provided a strong foundation for more indepth examination of the existing practices of school leadership.

\section{References}

Abdullah, Sarimah; Shaik, Hashim; Rosna, Awang; and Norman, Mohammad (2016). Contextual leadership practices: The case of a successful school principal in Malaysia. Educational Management Administration and Leadership, 25, pp. 1-7. doi: 10.1177/1741143216665840.

Creswell, John W. (2007). Qualitative inquiry research design: Choosing among five approaches (2nd ed.). Thousand Oaks: Sage. 
Creswell, John W. (2013). Educational research: Planning, conducting and evaluating quantitative and qualitative research (4th ed.). New Delhi: PHI Learning Private Limited.

Day, Christopher; Harris, Alma; Hopkins, David; and Sammons, Pam (2013). Successful school leadership what it is and how it influences people learning. Research Gate. CFBT Education Trust, Retrieved from https://www.researchgate.net/publication/238717790.

Denzin, Norman K.; and Lincoln, Yvonna S. (2011). Introduction: The discipline and practice of qualitative research, in Denzin, N.K. and Y.S. Lincoln (eds.). The Sage handbook of qualitative research (4th ed.). Thousand Oaks, CA: Sage.

Denzin, Norman K. and Lincoln, Yvonna S. (2018) (eds.). A Sage Handbook of Qualitative Research (5th ed.). Thousand Oaks: Sage

Denzin, Norman K. and Lincoln, Yvonna S. (2005) (eds.). The Sage handbook of qualitative research (3rd ed.). Thousand Oaks, CA: Sage.

Gurr, David. (2015). A model of successful school leadership from the international successful school principalship project. Societies, 5, pp. 136-150. doi: 10.3390/soc501036.

Gurr, David; Drysdale, Lawrie; and Mulford, Bill. (2010). Australian principal instructional leadership. Magis, 2(4). Pp. 299-314.

Harris, Alam; Hopkings, David; and Leithwood, Kenneth. (2008). Seven strong claims about successful school leadership. School Leadership and Management. 28(1), pp. 27-42. doi:10.1080/13632430701800060.

Louis, Karen Seashore; Leithwood, Kenneth; Wahlstrom, Kyla and Anderson, Stephen. (2010). Learning from Leadership: Investigating the links to improved student learning. Final Report of Research to the Wallace Foundation, University of Minnesota.

Robinson, Viviane; Hohepa, Margie; and Lloyd, Claire. (2009). School leadership and student outcomes: Identifying what works and why. Best Evidence Synthesis Iteration. Wellington: Ministry of Education.

Weinstein, Jose; Azar, Ariel; and Flessa, Joseph. (2017). An ineffective preparation? The scarce effect in primary school principals' practices of school leadership preparation and training in seven countries in Latin 
America. Educational Management Administration and Leadership, 249, pp. 1-32. doi: 10.1177/1741143217728083.

Yin, Robert K. (2003). Case study research: Design and methods (3rd ed.). Thousand Oaks: Sage.

Yin, Robert K. (2016). Qualitative research from start to finish (2nd ed.). New York: The Guilford Press. 